\title{
Optimal Predictive Criteria for Common Bile Duct Stones: The Search Continues
}

\author{
Yun Nah Lee and Jong Ho Moon \\ Digestive Disease Center and Research Institute, Department of Internal Medicine, Soonchunhyang University School of Medicine, \\ Bucheon, Korea
}

See "Evaluating the Revised American Society for Gastrointestinal Endoscopy Guidelines for Common Bile Duct Stone Diagnosis" by Jake S. Jacob, Michelle E. Lee, Erin Y. Chew, et al., on page 269-274.

Of all patients with symptomatic gallbladder stones, 10-20\% are diagnosed with concomitant common bile duct (CBD) stones. Suspected CBD stones should be removed via endoscopic retrograde cholangiopancreatography (ERCP). However, ERCP has a significant risk (6-15\%) of major adverse events, including post-ERCP pancreatitis, bleeding, cholangitis, and perforation. ${ }^{1}$ Therefore, it is important to select appropriate candidates for ERCP in order to avoid unnecessary ERCP.

The American Society for Gastrointestinal Endoscopy (ASGE) guidelines of 2010 recommended stratification of the CBD stone risk, determined by baseline biochemical tests and abdominal ultrasonography (US), when considering ERCP. ${ }^{2}$ The guidelines defined high risk ( $>50 \%$ ) as meeting one of the following four criteria: CBD stones evident on abdominal US, bilirubin (Bb) level $>4 \mathrm{mg} / \mathrm{dL}$, Bb level $1.8-4.0 \mathrm{mg} / \mathrm{dL}$ and a dilated CBD apparent on abdominal US, or evidence of clinical cholangitis. The guidelines recommend that high-risk patients proceed directly to ERCP. However, several validation studies have shown that $20-30 \%$ of cases undergo diagnostic

Received: February 23, 2021 Revised: March 4, 2021

Accepted: March 5, 2021

Correspondence: Jong Ho Moon

Digestive Disease Center and Research Institute, Soonchunhyang University Bucheon Hospital, 170 Jomaru-ro, Wonmi-gu, Bucheon 14584, Korea

Tel: +82-32-621-5094, Fax: +82-32-621-5080, E-mail: jhmoon@schmc.ac.kr ORCID: https://orcid.org/0000-0002-3946-9944

(c) This is an Open Access article distributed under the terms of the Creative Commons Attribution Non-Commercial License (http://creativecommons.org/ licenses/by-nc/3.0) which permits unrestricted non-commercial use, distribution, and reproduction in any medium, provided the original work is properly cited.
ERCP only (no stones). ${ }^{3-5}$

In 2019, the ASGE updated their guidelines with the goal of improving pretesting to reduce the number of diagnostic ERCP. $^{6}$ The high-risk CBD stone criteria were simplified to one of the following: 1) CBD stones evident on US or cross-sectional imaging, 2) total $\mathrm{Bb}$ level $>4 \mathrm{mg} / \mathrm{dL}$ and a dilated $\mathrm{CBD}$, or 3) ascending cholangitis.

In this issue of Clinical Endoscopy, Jacob et al. ${ }^{7}$ compared the diagnostic accuracies of the original 2010 and revised 2019 guidelines and assessed the performance of each set of criteria. In a retrospective analysis of 267 patients, the 2019 high-risk criteria improved the specificity from 55\% (2010 guidelines) to $80 \%$ and the positive predictive value from $79 \%$ to $83 \%$. The diagnostic ERCP rate decreased from $21 \%$ to $17.4 \%$, which is consistent with the goal of minimizing diagnostic ERCP.

In a recent paper, the performance of endoscopic ultrasound (EUS) and magnetic resonance cholangiopancreatography (MRCP) in diagnosing CBD stones was comparable with that of ERCP, but EUS and MRCP are associated with much lower risks of adverse events relative to those with ERCP. ${ }^{8}$ Therefore, the guidelines have been revised to reduce the proportion of high-risk CBD stone patients and increase that of intermediate-risk patients who are recommended to undergo further evaluation employing EUS, MRCP, laparoscopic intraoperative cholangiography, or laparoscopic intraoperative US.

The European Society of Gastrointestinal Endoscopy (ESGE) guidelines for endoscopic management of CBD stones uses a simple criterion to define a high risk of CBD stonesfeatures suggestive of cholangitis or CBD stones identified using US. ${ }^{9}$ The ESGE guidelines do not include the $\mathrm{Bb}$ level 
or presence of a dilated CBD on US. In a recent study, Jagtap et al. ${ }^{10}$ compared the clinical utility of the revised ASGE and ESGE guidelines in terms of risk stratification. The specificity and positive predictive value were $96.87 \%$ and $89.57 \%$, respectively, using the ASGE high-risk criteria versus $98.96 \%$ and $96.24 \%$, respectively, using the ESGE high-risk criteria. Among 17 patients with a $\mathrm{Bb}$ level $>4 \mathrm{mg} / \mathrm{dL}$ and a dilated CBD evident on US (ASGE criteria), only one had CBD stones. In addition, the ASGE guidelines identified 58 (8.6\%) additional patients as being at intermediate risk because they were aged $>55$ years; none had CBD stones. Thus, removing age $>55$ years from the ASGE intermediate-risk criteria would reduce the requirement for further diagnostic procedures (such as EUS or MRCP) in $8.6 \%$ of patients.

As diagnostic imaging methods with good performance for $\mathrm{CBD}$ stones emerge, the criteria for high-risk $\mathrm{CBD}$ stones should include only those cases where the CBD stone is objectively identified using imaging tests. However, the diagnostic performance of each modality, such as EUS and MRCP, can differ according to the stone size and type. In addition, we should consider local availability and operator expertise for EUS and MRCP. Therefore, CBD stone risk stratification remains controversial, and a more accurate algorithm using clinical features is still needed. The cost-effectiveness of such algorithms must also be evaluated.

Conflicts of Interest

The authors have no potential conflicts of interest.

Funding

None.
ORCID

Yun Nah Lee:

https://orcid.org/0000-0001-5588-784X

Jong Ho Moon:

https://orcid.org/0000-0002-3946-9944

\section{REFERENCES}

1. Freeman ML, Nelson DB, Sherman S, et al. Complications of endoscopic biliary sphincterotomy. N Engl J Med 1996;335:909-918.

2. ASGE Standards of Practice Committee, Maple JT, Ben-Menachem T, Anderson MA. The role of endoscopy in the evaluation of suspected choledocholithiasis. Gastrointest Endosc 2010;71:1-9.

3. He H, Tan C, Wu J, et al. Accuracy of ASGE high-risk criteria in evaluation of patients with suspected common bile duct stones. Gastrointest Endosc 2017;86:525-532.

4. Adams MA, Hosmer AE, Wamsteker EJ, et al. Predicting the likelihood of a persistent bile duct stone in patients with suspected choledocholithiasis: accuracy of existing guidelines and the impact of laboratory trends. Gastrointest Endosc 2015;82:88-93.

5. Magalhães J, Rosa B, Cotter J. Endoscopic retrograde cholangiopancreatography for suspected choledocholithiasis: from guidelines to clinical practice. World J Gastrointest Endosc 2015;7:128-134.

6. ASGE Standards of Practice Committee, Buxbaum JL, Abbas Fehmi SM, et al. ASGE guideline on the role of endoscopy in the evaluation and management of choledocholithiasis. Gastrointest Endosc 2019;89:10751105.e15.

7. Jacob JS, Lee ME, Chew EY, Thrift AP, Sealock RJ. Evaluating the revised American Society for Gastrointestinal Endoscopy guidelines for common bile duct stone diagnosis. Clin Endosc 2021;54:269-274.

8. Tse F, Liu L, Barkun AN Armstrong D, Moayyedi P. EUS: a meta-analysis of test performance in suspected choledocholithiasis. Gastrointest Endosc 2008;67:235-244

9. Manes G, Paspatis G, Aabakken L, et al. Endoscopic management of common bile duct stones: European Society of Gastrointestinal Endoscopy (ESGE) guideline. Endoscopy 2019;51:472-491.

10. Jagtap N, Hs Y, Tandan M, et al. Clinical utility of ESGE and ASGE guidelines for prediction of suspected choledocholithiasis in patients undergoing cholecystectomy. Endoscopy 2020;52:569-573. 